In the type of motion which is consistent with a constant value of the energy the velocity of an electron belonging to the ring is directly proportional to the radius of its sphere of interference; this corresponds to a uniform motion in the symmetrical configuration, and may be derived from it by a conformal transformation. The assumptions made with regard to the mass of an electron and the interference of radiations at the nodes may be justified if the velocity of light within a sphere of interference is directly proportional to the radius.

The combination of a positive and negative ion may be pictured by supposing that the extra sphere belonging to the negative ion partly fits into the gap in the positive ion in such a way that it is in contact with two spheres belonging to the ring in the positive ion, and the atomic spheres of the two atoms are in contact. This would give three additional geometrical conditions. It should be noticed that the electrons would be nearer together close to the point of contact, so that the greater part of the mass would be concentrated round this point.

The connection between the number of degrees of freedom and valency is discussed in a paper which will appear shortly in the Memoirs of the Manchester Literary and Philosophical Society.

The University, Manchester.

\section{Silk-producing Insects of West Africa}

THE following observations in connection with the wild silk-producing insects of West Africa may be considered of interest. In parts of Nigeria (Ibadan, Ilorin, \&c.) the cocoons of Anaphe infracta, Wlsm., and A. venata, Butler, are used for the production of a cloth termed "Sanyan," which is woven from yarn, spun from the boiled cocoon masses, mixed with native cotton yarns. In a state of nature the silk from the cocoons of both these species is brown or yellow-brown, and is of this colour when exposed for sale in the markets, but another kind of silk, which is brought to Ibadan from Bauchi and Bornu (in N. Nigeria), is pure white in colour, and is called "Gambari," or Haussa silk. This is only obtainable as boiled cocoon masses, and the dried remains of the worms found in them seem to indicate that they are allied to Anaphe. The collectors of this silk are said to gather the worms from the trees, on which they find them, when they are prepared to spin, and to confine them in calabashes.

Experimenting with live worms of $A$. infracta, received from S. Nigeria, I found that, by confining them in the dark, they produced pure white cocoons instead of brown, although the original larval cocoun was of the latter colour. It seems probable that the "Gambari" silk is white by reason of the confinement of the worms in calabashes, as no Anaphe or allied species is known to give a white cocoon naturally. A similar result has been obtained by Lepper in the case of Attacus ricini (the "Eri" silkworm of India)

The pupx of $A$. infracta and $A$. venata are eaten as a delicacy by the people of S. Nigeria. Both species seem almost omnivorous in the larva stage, but the first is said to feed, by preference, upon Albizzia fastigiata and a Sterculia sp.

A. Maloneyi and A. subsordida, the first of which has apparently a cocoon mass without an envelope, should, I think, be placed in another genus, by reason of the absence from their forewings of the lower radial vein (No. 5).

Imperial Institute, November I7. Gerald C. Dudgeon.

\section{Vitality of Leaves.}

1 HAVE in my possession a sprig of Bryophyllum calycinum which was cut off a plant in Jamaica six months ago, at the beginning of June. It has still attached to it three leaves, which are quite green, and at the edges of these there are minute new shoots projecting from the crenations. Only a fortnight ago a leaf plucked from it showed its vitality by giving rise to a new shoot when placed on some soil in a pot. This shoot is growing well under a glass in a warm room. During all these months this small sprig has been lying about in different rooms, without any supply of soil or moisture.
Could any of your botanical readers inform me if this degree of vitality, in a detached portion of a plant, is unusual?

December 7 .

\section{The Exhibition of Fishes in Museums.}

THERE are at least four museums in the United States in which collections of fishes are exhibited " in which the specimens are presented without the usual iron supports, with sufficient space around each fish and in natural colours" (NATuRE, October 29, vol. lxxviii., p. 659). These institutions are the Field Museum of Natural History, Chicago ; Museum of Comparative Zoology, Cambridge; American Museum of Natural History, New York, and Museum of the Brooklyn Institute.

Furthermore, the last-named museum has an attractive group of fishes of a coral reef amid their natural surroundings, and the Field Museum has two groups of freshwater game fishes.

F. A. Lucas.

Museum of the Brooklyn Institute, Eastern Parkway, Brooklyn, N.Y.

\section{An Electromagnetic Problem.}

THE electromagnetic problem enunciated by Prof. Comstock in NATURE of November I9 admits of being solved without any reference to the corpuscular nature of electricity and without going beyond the basis of Maxwell's theory.

If $\sigma$ be the surface density of the sphere, $r$ its radius at any time, the value of the vector potential at a distance $\mathrm{R}$ is $\frac{4}{3} \pi \sigma \dot{r} r^{3} \mathrm{R}^{-3}(x, y, z)$.

Making use of Maxwell's first expression for kinetic energy, $\frac{1}{2}(\mathrm{~F} u-\mathrm{G} v+\mathrm{H} w)$, we get for the kinetic energy $\frac{1}{8}\left(4 \pi \sigma r^{2}\right)^{2} \dot{\gamma}^{2} r-1$, from which the problem can be completed. To understand the question fully we must use the retarded formulæ for the potentials, Maxwell's expression being only the first terms of expansions in descending powers of $C$, the velocity of radiation. We get in this way more complicated values of the potentials, giving, however, no magnetic force and the original symmetrical electric force.

The question is interesting as supporting Macdonald's view as to the expression for the energy. It also seems to point out that in any æether theory the vector potential must be looked upon as something more than a mathematical abstraction.

Cosy Nook, roo Leinster Road, Rathmines,

December I.

\section{Mercury Bubbles.}

I HAVE often observed these bubbles when purifying mercury. They may be produced very easily by shaking mercury and any liquid in a wide stoppered test-tube, and then suddenly bringing the tube to rest, when the bubbles (of varying size) will be formed.

I have tried the following liquids:--water, alcohol, ether, acetone, ethyl acetate, acetoacetic ester, amyl nitrite, amyl alcohol. amyl acetate, carbon tetrachloride, benzene, toluene, xylene, gelatin, glycerin, formic acid, acetic acid, aniline, carbun bisulphide, toluidine, pyridine, ethyl iodide, methyl bromide, ethyl bromide, methyl iodide, dichloroethylene, ethylene dibromide, chloroform; it seems that the more volatile and less viscous the liquid, the smaller are the bubbles and the quicker do they burst.

\section{Hackney Technical Institute, N.E.}

In view of the several letters about mercury bubbles which you have recently published, I beg to mention that molten steel is also capable of forming bubbles. If a bucket full of water be placed in a suitable position underneath and a little to the front of a Bessemer converter, then on removing the bucket after the completion of a blow it will be found to contain small spheres of steel ranging in size from a pin's head to that of peas, and even larger. These spheres are hollow, and some are perforated, and occasional ones are twins and triplets, sets of hollow spheres having plunged into the water at the instant thev stuck together.

West Didsbury.

C. E. Stromeyer. 